\title{
A Study of the International Students' Motivation to Study Chinese
}

\author{
Qiao Hengyu \\ School of Foreign Languages, China Three Gorges University, Yichang, China
}

Email address:

feiyue277@163.com

\section{To cite this article:}

Qiao Hengyu. A Study of the International Students' Motivation to Study Chinese. International Journal of Language and Linguistics. Vol. 4, No. 4, 2016, pp. 147-152. doi: 10.11648/j.ij11.20160404.12

Received: July 8, 2016; Accepted: July 18, 2016; Published: July 29, 2016

\begin{abstract}
Many linguists, such as Lightbown \& Spada, have proved that motivation is very important for language learning, especially for the second language learning. Chinese language is the compulsory course in many universities in China and many international students, especially the undergraduates major in technology or engineering can't do it well. Through the survey and analysis of it, this study shows that teachers had put too much attention on sparing international students' extrinsic motivation and ignores the intrinsic motivation. The effective teaching method is sparing students' intrinsic motivation from the perspective of Chinese culture.
\end{abstract}

Keywords: Motivation, SLA, Chinese Courses, International Students

\section{Introduction}

The foreign language learning motivation refers to the choice and effort the learners make to achieve his or her foreign language learning goal [14]. Motivation is proved to play an important role in Second language Acquisition (SLA), which is thought to be the predictor of language learning success. With the development of Chinese economic, Chinese language has become more and more important around the world. Recent years, more and more international students come to China to study and live there. As an international student in CTGU, Chinese is a compulsory course which these students have to pass to get their graduation diploma. As they live in the Chinese language community, international students need to communicate with their Chinese teachers and peers. Although most of Chinese teachers and students in universities can speak English, their English aren't as good as their Chinese. This need pushed the international students to master Chinese as a practical communicating tool. If learners need to speak the second language in a wide range of social situations or to fulfill professional ambitions, they will perceive the communicative value of the second language and will therefore be motivated to acquire proficiency [8]. However, is it the motivation for college international students who seldom use their Chinese to communicate with each other in daily life to study Chinese? If not, what is their motivation? And how important the motivation is in their study?

There has been a great deal of studies on the role of attitudes and motivation in second language learning. Mackey \& Gass argue that the research framework based on the linguistics, psychology and sociology. It means that linguists must take the linguistic factor, psychological factor and sociological factor into their consideration when they do the relative research. The combination of these three types of factors is learner's motivation [9]. "The overall findings show that positive attitudes and motivation are related to success in second language learning." [6] In 1970s, the concentration of foreign or second language learning has shifted from the focus of teacher and teaching to the focus of students and learning. This change indicates that much more attention is put on the individual instead of the group. In recent years, researchers begin to concentrate on the factor which affects SLA, including motivation, environment, creativity, emotions etc. Among these factors, motivation is no doubt a vital research field in Second Language Acquisition. As Lightbown \& Spada point out that "we should keep in mind that an individual's identity is closely linked with the way he or she speaks." [8] The reason is that language acquisition is tightly connected with the individual and motivation.

This paper will study the motivation of study Chinese of the International students from College of Civil Engineering and 
Architecture, China Three Gorges University (CTGU).

\section{Literature Review of Motivation}

\subsection{The Definition of Motivation}

At first, motivation is a concept of psychology which is connected with study and then it is introduced into linguistics. Dörnyei thinks that different language learners have different study motivations, attitudes and effort levels which affect learners' attention and internalization [3]. The general definition of motivation is given by Ames. R. S \& Ames. C. "Motivation is theoretical concept that accounts for why people choose to engage in particular activities at particular times." [1] More specific definitions of motivation in L2 learning were given by Gardener. He puts that motivation as combination of efforts with the desire to achieve the goal of learning the languages plus favorable attitudes towards learning the languages [6].

Besides, motivation is an important factor of L2 learning. As Dörnyei points out that motivation is one of the main determinants of second /foreign language (L2) learning achievement and, accordingly, the last three decades have seen a considerable amount of research that investigates the nature and role of motivation in the L2 process [5]. Therefore, motivation is the concept that explains why people do something or not do something at a certain time. In the field of language learning, motivation can be divided into two parts, i.e. the need for communication and the attitude to the language community. All of these definitions have something in common, i.e. motivation is the psychological reason beyond a person's actions. Although they define motivation from different perspectives, motivation is dominant factor in L2 learning.

\subsection{Categorization of Motivation}

As discussed above, motivation has different definitions from different perspectives. Therefore, there are some different categorizations of motivation based on the different definitions. This part will introduce two types of categorization of motivation from different perspectives.

\subsubsection{Integrative \& Instrumental Motivation}

Motivation structure has often been understood as the interplay of two components, i.e. integrative and instrumental motivations. The former is associated with a positive disposition towards the L2 group and the desire to interact with and even become similar to valued members of that community. The latter is related to the potential pragmatic gains of L2 proficiency, such as getting a better job or higher salary [5].

Gardner classifies motivation into two types, i.e. integrative and instrumental motivation. Integrative motivation is a type of innate motivation which includes positive attitudes towards the language community and the desire to communicate with members of the target language group [6]. Instrumental motivation is a type of outside motivation which can be seen as an external stimulation such as job opportunities, good goals on the text paper and rewards from parents.

This categorization reveals the basic types of motivation. However, this categorization is still uncompleted and unsatisfied. The definition of instrumental motivation given by Gardner only refers to the positive aspect and it doesn't refer to the other aspect of motivation i.e. avoid punishment or loss.

\subsubsection{Intrinsic \& Extrinsic Motivation}

Noels argues that there are two general types of motivation. One based on the intrinsic interest in the activity per se and the other based on rewards extrinsic to the activity itself [12]. The categorization of extrinsic motivation and intrinsic motivation is, to some degree, a development of Gardner's categorization.

Intrinsic motivation (IM) generally refers to motivation to engage in an activity because that activity is enjoyable and satisfying to do [12]. Intrinsic motivation in L2 learning includes the desire to improve, the enjoyment of achieving the goal, and study interest. For intrinsically motivated behaviors, the rewards are internal such as the joy of doing a particular activity or satisfying one's curiosity. In contrast to intrinsically motivated behaviors, extrinsically motivated behaviors are those actions carried out to achieve some instrumental end [12]. Extrinsic motivation (EM) includes earning a reward such as good grades, good job opportunity and praise from parents, or avoiding a punishment. From this point, extrinsic motivation can be seen as the complement. It reveals the psychological factors beyond the extrinsic motivation i.e. acquire advantages and avoid disadvantages.

\subsection{International and Domestic Studies of Motivation}

Motivation is such a hot topic in applied linguistic that there are a lot of researchers, such as Grander, Lambert, Deci \& Maslow, devote themselves into this study. In western countries, Gardner \& Lambert are the founders of this study. In 1950s, Gardner and Lambert pioneered the research on motivation and made the well known distinction between integrative and instrumental orientation in motivation [11]. This categorization laid a solid foundation of the future study. Although this categorization is the milestone of motivation study, this categorization, as what discussed above, also has something to improve. Based on the categorization given by Grander, Brown introduced another categorization of motivations i.e. intrinsic motivation and extrinsic motivation. After this categorization was put forward, it is argued fiercely which one is more important between these two motivations. Maslow puts that extrinsic motivation is inferior to intrinsic motivation. In his self-actualization theory, people will be motivated to realize "self-actualization" no matter what extrinsic reward is offered or not once the basic needs are met [10]. Deci \& Ryan have some closed viewpoints. They figure out that intrinsic motivation is in evidence whenever students' natural curiosity and interest energies their learning [2]. When the educational environment provides optimal challenges, rich sources of stimulation, and a context of autonomy, this motivational wellspring in learning is likely to flourish. 
Another question is whether motivation is fixed. Deci \& Ryan's self-determination theory suggests that motivation is a dynamic factor [2]. For a long time, psychologists have thought that motivation was a variant of the study.

Researchers from China have conducted the study on motivation since the 1980s. At first, these researchers paid attention to introducing the basic theory of motivation from abroad. Wen Qiufang, Wang Chumin, and Gui Shichun were the pioneers in this field of China. In Wang Chunming's paper, The Foreign Language Learning Model of Chinese Students, he points out that instrumental motivation is the leading type of motivation of Chinese students in SLA [13]. Lian Jie does the research on factors which affect study strategy. Lian jie argues that among these factors, attitude affects and decides the motivation [7]. With the development of the study of this field, Chinese researchers begin to shift their academic interests to focus on the practical issues related to language teaching and learning. They applied the motivation theory in their teaching.

\section{Investigation}

\subsection{Research Questions}

This study tries to give the answers to these questions

(1) What is the motivation of international students to learn Chinese?
(2) Does the motivation play an important role in their studying?

(3) Is intrinsic or extrinsic motivation more important in Chinese language study?

(4) What can teachers do to use the findings to improve students' study of Chinese?

\subsection{Methodology}

To answer the questions above, a questionnaire survey was given to international students from College of Civil Engineering and Architecture, CTGU. These students come from India, Pakistan, Bangladesh and Nepal. Most of them didn't learn Chinese before they come to China. This questionnaire investigates 20 students ranged from grade two to grade three. All of them are male. Each questionnaire has 20 questions and each question gives three choices, i.e. Yes, No, and Not sure. These questions are collected from Internet such as www.baidu.com and www.sogo.com. All the students were required to answer this questionnaire in 15 minutes independently without any communication with their classmates. This questionnaire is handed out through QQ group (a kind of Internet communication tool popular in China). It took the author one week to analyze the data collected from the survey

\subsection{Major Findings and Analysis}

\subsubsection{Major Findings}

Table 1. The Results Diagram of Questionnaires for International Students.

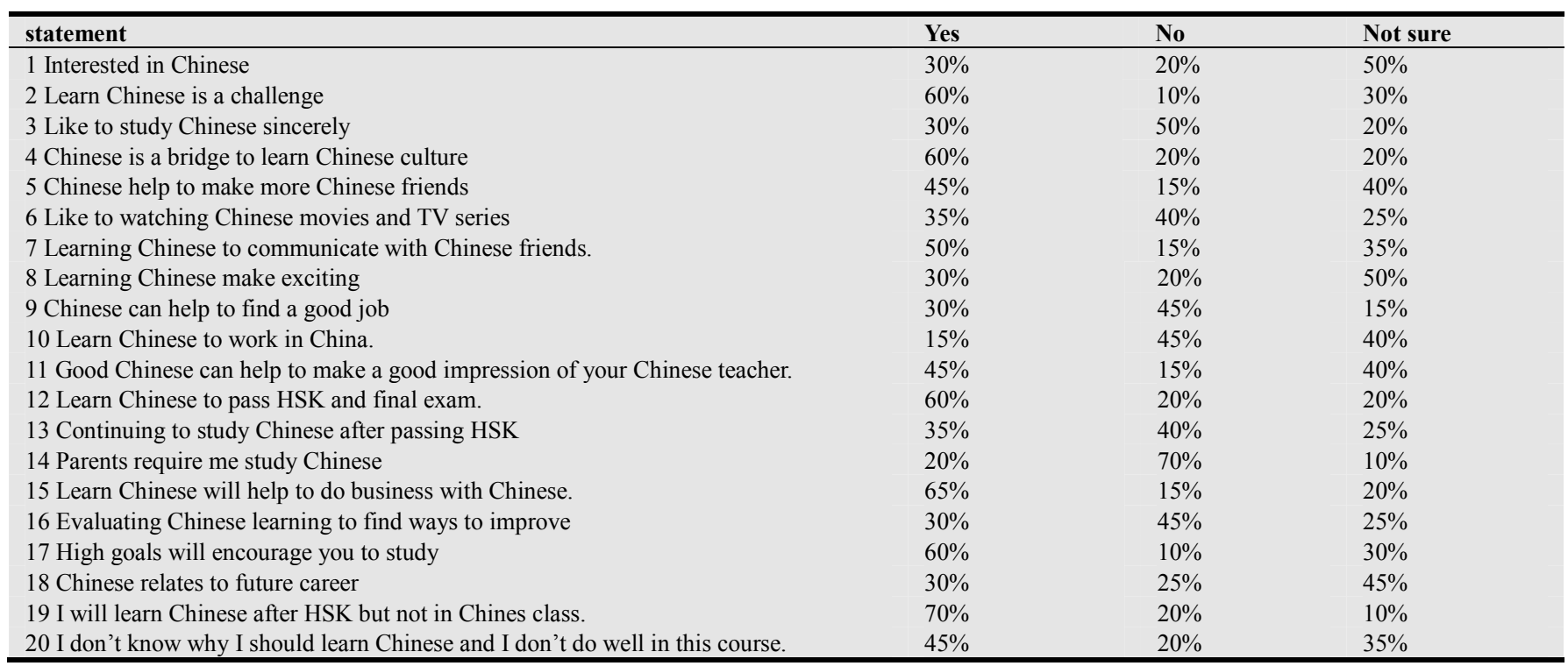

From the above diagram, some interesting phenomenon can be seen. Firstly, the first statement is related to intrinsic motivation of Chinese learning and it is a basic question to test students. There are $30 \%$ of the students choose "yes" $20 \%$, who choose "no" and $50 \%$ who choose "not sure". This result implies that half of the international students lack intrinsic motivation of learning Chinese. The second statement is to test the attitudes of the students towards Chinese learning. The result indicates that $60 \%$ of the students think that learning Chinese is a challenge for them and only $10 \%$, i.e. 2 students, of the students don't think so. There are $40 \%$ of the students who are not sure. This finding explains that more than half of the students suffer the stress of learning Chinese. Statements from 3 to 8 are related to the 
intrinsic motivation they have for learning Chinese. These questions aim to find out what kind of intrinsic motivation of English learning and how important these motivations are in their learning. From the results, for statement 3, there are $30 \%$ of the students who say that they like to learn Chinese sincerely. This is a basic question. From the statements 4 to 8 , these questions aim to find what kind of intrinsic motivation they have and how important its role is in Chinese learning. The results of these statements indicate that intrinsic motivations play an important role in the Chinese language learning of international students. Among these intrinsic motivations, learning Chinese as a bridge to learn Chinese culture is the chief motivation for students and learning Chinese to watch Chinese movies and TV series are least important motivations. This result is probably because the international students can't understand Chinese movies and TV series for their poor Chinese language skill. Statements from 9 to 18 are related to extrinsic motivation of Chinese learning. From the data collected in the diagram, compared to the statements from 4 to 8 , it can be seen that extrinsic motivation also plays an important role in Chinese learning. From these results, getting a good goals on the exam paper and their probable future career with Chinese in the future become the two primary motivations push them to learn Chinese. Another important motivation for international students to learn Chinese is to pass the HSK test. The diagram shows that there are $60 \%$ of students whose reasons to learn Chinese is to pass the HSK test. In contrast, there are only $35 \%$ of the students want to continue to Chinese course. However, there still $70 \%$ international students will choose to learn Chinese out of their class such as learn Chinese from their Chinese friends.

\subsubsection{Analysis of Findings}

From all the data above, the results which can help teachers understand international students' study motivation. Firstly, intrinsic motivation is much weightier than the extrinsic motivation. As what Deci \& Ryan argue that intrinsic motivation is, potentially, a central motivator of the educational process [2]. Secondly, among the extrinsic motivations, passing HSK and Chinese language final exam is the primary motivation. This result shows that an appropriate test can spur international students work hard on their Chinese learning. However, only $35 \%$ of the students like to watch Chinese movies and TV series. This result shows that they can't only understand the Chinese literal meaning but also the culture behind it. Therefore, teachers who teach international students Chinese language should teach the students the pronunciation, grammar and words etc. of Chinese as well as demonstrate Chinese culture. Besides, the factors make the learners perform differently referring to working memory, study anxiety and tolerance of ambiguity [9]. If the teacher can follow those suggestions, the intrinsic motivation of international students will be spurred and the students will master Chinese better. Therefore, teachers should take the individual factor into the consideration when they choose some information to do language teaching [14].

\section{Discussion}

\subsection{Answers to the Research Questions}

(1) The primary motivations of international to learn Chinese are getting good goals in their Chinese course exam, passing HSK and their future career with Chinese.

(2) Motivation plays an important role in Chinese learning. If a student doesn't have a clear motivation in learning second language, they will not do it well.

(3) Intrinsic motivation is an important factor for international students learning Chinese. Although test is an effective method to make international students pay their attention on learning Chinese, teachers shouldn't rely on it as the only way to spur them to study.

(4) The huge barrier for international students to learn Chinese is lack the knowledge of Chinese culture. Generally thinking is that the pronunciation of Chinese is the most difficult for international students to master. The fact is how to help international students understand Chinese culture is more difficult. Therefore, Chinese language teaching shouldn't only concentrate on the language skill but also, to some degree it is more important, on the culture teaching.

\subsection{Intrinsic Motivation and Extrinsic Motivation}

As what this study discussed above, intrinsic motivation and extrinsic motivation are the two aspects of study motivation. From the data collected in the survey, it is found that extrinsic motivation, such as getting good goals, passing the HSK and the future career. Applied linguistics (and educational psychology in general) has typically followed an individual difference-based approach to integrate learner characteristics into the various research paradigms [4]. As for intrinsic motivation can be seen as the chief motivation of international students, intrinsic motivation should be paid more attention to. Extrinsic motivation has traditionally been seen as something that can undermine intrinsic motivation; several studies have confirmed that students will lose their natural interest in an activity if they have to do it to meet some extrinsic requirement [5]. Therefore, intrinsic motivation should play a core role in Chinese learning.

\section{Conclusions}

This study aims to identify the motivation of international students to learn Chinese. Motivation is an important factor for international students to learn Chinese well. The results of this survey and its analysis revealed the real motivation of international students. With the development of China, there is a great deal of international students come to China to study. Besides, China's influence becomes more and more huge. Therefore, teaching Chinese as a second language for people from other countries should be paid more attention on.

However, traditional language teaching pays too much 
attention on the extrinsic motivation and ignores the importance of the intrinsic motivation. Giving more emphasis on extrinsic motivation will eventually make students lose their interest in Chinese learning. The effective teaching method is sparing students' intrinsic motivation from the perspective of Chinese culture. To realize this goal, teacher should take full advantage of all methods to stimulate students' innate power to make their learning more effective.

\section{Appendix}

Questionnaire

1 Are you interested in Chinese?
A Yes
B No
C Not sure

2 For you, learning Chinese is a challenge?
A Yes
B No
C Not sure

3 Are you like to study Chinese sincerely?
A Yes
B No
C Not sure

4 Do you think learning Chinese is a bridge to learn Chinese culture?
A Yes
B No
C Not sure

5 Do you think learning whether learning Chinese can help to make more Chinese Friends?
A Yes
B No
C Not sure

6 Do you like to watch Chinese movies and TV SERIES?
A Yes
B No
C Not sure

7 You are learning Chinese for communicating with Chinese friends?
A Yes
B No
C Not sure

8 Learning Chinese make exciting
A Yes
B No
C Not sure

9 Do you think Chinese can help to find a good job?
A Yes
B No
C Not sure

10 Learning Chinese to work in China?
A Yes
B No
C Not sure

11 Do you think good Chinese can help to make a good impression of your Chinese teacher?
A Yes
B No
C Not sure

12 Do you Learn Chinese to pass HSK and final exam?
A Yes
B No
C Not sure

13 Will you continue to study Chinese after passing HSK?
A Yes
B No
C Not sure

14 Do your parents require me study Chinese?
A Yes
B No
C Not sure

15 Do you think learning Chinese will help to do business with Chinese?
A Yes
B No
C Not sure

16 Will you evaluate Chinese learning to find ways to improve?
A Yes
B No
C Not sure

17 Will high marks encourage you to study?
A Yes
B No
C Not sure 
18 Do you think Chinese relates to future career?
A Yes
B No
C Not sure

19 I will learn Chinese after HSK but not in Chines class.
A Yes
B No
C Not sure

20 I don't know why I should learn Chinese and I don't do well in this course.
A Yes
B No
C Not sure

\section{References}

[1] Ames. R. E. \& Ames. C. Research on Motivation in Education [M]. New York: Academic Press, 1984.

[2] Deci, E. L. \& Ryan, R. M. Intrinsic Motivation and Self-Determination in Human Behavior [M]. New York: Plenum Press. 1985.

[3] Dörnyei, Z. Teaching and Researching Motivation [M]. Beijing: Foreign Language Teaching and Research Press, 2007.

[4] Dörnyei, Z. Individual Differences: Interplay of Learner Characteristics and Learning Environment [J]. Language Learning, 2009.

[5] Dörnyei, Z. Motivation in Language Learning [M]. Shanghai: Shanghai Foreign Languages Education Press, 2012.

[6] Gardner, R. C. Social Psychology and Language Learning: The Role of Attitudes and Motivation [M]. London: Edward Arnold, 1985.

[7] Lian, Jie. The Learner's Factor Which Restricts Study Strategy [J]. Beijing: Foreign Language Teaching and Research, 1998 (6).

[8] Lightbown, P. M \& Spada, N. How Languages are learned [M]. Oxford University press, 1999.

[9] Mackey, A. \& Gass, S. Researches Methods in Second Language Acquisition: A Practical Guide [M]. Oxford: Wiley-Blackwell, 2012.

[10] Maslow, A. H. Motivation and Personality Dynamics [M]. New York: Harper \& Row. 1970.

[11] Oxford, R. 1. \& Shearin, J. Language Learning Motivation: Expanding the Theoretical Framework [J]. Modern Language Journal. Vol. 78, No 1, 1994.

[12] Noels, K. A. et al. Why are You Learning a Second Language? Motivational Orientations and Self-Determination Theory [J]. Language Learning, 2002.

[13] Wang, Chuming. The Foreign Languages Learning Model of Chinese Students [J]. Foreign Language Teaching and Research, 1989.

[14] Zhang, Sumin \& Chen, Xiankui. The Study of Effect of Foreign Language Learning Motivation Processing Salient Information [J]. Shanghai: Foreign Language World, 2015. 